Case Report

\title{
Autoimmune Hepatitis with Concomitant Idiopathic Thrombocytopenic Purpura Diagnosed by Transjugular Liver Biopsy
}

\author{
Hiromi Fukuda, ${ }^{1}$ Kazuhide Takata $\left(\mathbb{D},{ }^{1}\right.$ Takanori Kitaguchi, ${ }^{1}$ Ryo Yamauchi, \\ Hideo Kunimoto, ${ }^{1}$ Takashi Tanaka, ${ }^{1}$ Keiji Yokoyama, ${ }^{1}$ Daisuke Morihara, ${ }^{1}$ \\ Yasuaki Takeyama, ${ }^{1}$ Satoshi Shakado, ${ }^{1}$ Ai Mogi, ${ }^{2}$ Shinichi Kora, ${ }^{3}$ Kaori Koga, ${ }^{4}$ \\ Morishige Takeshita, ${ }^{4}$ Kengo Yoshimitsu, ${ }^{3}$ and Shotaro Sakisaka ${ }^{1}$ \\ ${ }^{1}$ Department of Gastroenterology and Medicine, Fukuoka University Faculty of Medicine, 7-45-1 Nanakuma, Jonan, \\ Fukuoka 814-0180, Japan \\ ${ }^{2}$ Division of Medical Oncology, Hematology and Infectious Disease, Department of Internal Medicine, \\ Fukuoka University Faculty of Medicine, 7-45-1 Nanakuma, Jonan, Fukuoka 814-0180, Japan \\ ${ }^{3}$ Department of Radiology, Fukuoka University Faculty of Medicine, 7-45-1 Nanakuma, Jonan, Fukuoka 814-0180, Japan \\ ${ }^{4}$ Department of Pathology, Fukuoka University Faculty of Medicine, 7-45-1 Nanakuma, Jonan, Fukuoka 814-0180, Japan
}

Correspondence should be addressed to Kazuhide Takata; edihuzak_t@yahoo.co.jp

Received 11 September 2018; Revised 14 October 2018; Accepted 29 November 2018; Published 9 December 2018

Academic Editor: Julio M. F. Chebli

Copyright (C) 2018 Hiromi Fukuda et al. This is an open access article distributed under the Creative Commons Attribution License, which permits unrestricted use, distribution, and reproduction in any medium, provided the original work is properly cited.

\begin{abstract}
Patients with autoimmune hepatitis (AIH) may sometimes have concomitant idiopathic thrombocytopenic purpura (ITP). Severe thrombocytopenia in ITP interferes with percutaneous liver biopsy for pathological diagnosis of AIH. Here, we report a case of AIH with ITP in a 63-year-old woman. The patient presented to our hospital with liver dysfunction and thrombocytopenia. For histological examination, transjugular liver biopsy (TJLB) was performed, leading to a diagnosis of AIH. Corticosteroids treatment led to an improvement in her liver enzyme levels and platelet count. In conclusion, patients with AIH may sometimes have concomitant ITP. TJLB was effective for making the diagnosis of AIH with severe thrombocytopenia due to ITP.
\end{abstract}

\section{Introduction}

Autoimmune hepatitis (AIH) is characterized by chronic inflammation of the liver, hypergammaglobulinemia and production of autoantibodies, and a favorable response to immunosuppressive therapy. Histological examination, which tends to reveal interface hepatitis and plasma cell infiltration, is important for the diagnosis of AIH [1]. AIH can often occur in the setting of other nonhepatic autoimmune disorders, such as chronic thyroiditis (7.5\%) and Sjögren's syndrome (5.7\%); however, concomitant AIH and idiopathic thrombocytopenic purpura (ITP) is rare (0.6\%) [2].

Percutaneous liver biopsy (PLB) is the standard method for obtaining a liver procuring tissue for histological examination. When it is contraindicated because of the risk of postprocedure hemorrhage, transjugular liver biopsy (TJLB) is recommended.

Here, we report a case of AIH associated with ITP, in which TJLB was useful in making the diagnosis and prompts start of treatment with a corticosteroid.

\section{Case Presentation}

A 63-year-old woman with no significant medical history was referred to our hospital for further investigation of elevated liver enzyme levels and thrombocytopenia. The patient had a few days' history of general malaise and purpura of her legs. She had no fever or any abdominal complaints. She had a history of alcohol intake of about $40 \mathrm{~g} /$ day and no constant drug use. 
TABLE 1: Laboratory data on admission.

\begin{tabular}{|c|c|c|}
\hline \multicolumn{3}{|l|}{ Hematology } \\
\hline White blood cell & 5,100 & $/ \mu \mathrm{L}$ \\
\hline Red blood cell & 482 & $10^{\wedge} 6 / \mu \mathrm{L}$ \\
\hline Hemoglobin & 14.9 & $\mathrm{~g} / \mathrm{dL}$ \\
\hline Platelets & 22 & $10^{\wedge} 3 / \mu \mathrm{L}$ \\
\hline \multicolumn{3}{|l|}{ Coagulation } \\
\hline PT\% & 95 & $\%$ \\
\hline PT-INR & 1.03 & \\
\hline APTT & 26.1 & \\
\hline \multicolumn{3}{|l|}{ Biochemistry } \\
\hline Albumin & 3.9 & $\mathrm{~g} / \mathrm{dL}$ \\
\hline Total bilirubin & 8.8 & $\mathrm{mg} / \mathrm{dL}$ \\
\hline Direct bilirubin & 6.0 & $\mathrm{mg} / \mathrm{dL}$ \\
\hline AST & 1,767 & $\mathrm{U} / \mathrm{L}$ \\
\hline ALT & 1,845 & $\mathrm{U} / \mathrm{L}$ \\
\hline GGT & 2,229 & $\mathrm{U} / \mathrm{L}$ \\
\hline ALP & 845 & $\mathrm{U} / \mathrm{L}$ \\
\hline Amylase & 39 & $\mathrm{U} / \mathrm{L}$ \\
\hline BUN & 10 & $\mathrm{mg} / \mathrm{dL}$ \\
\hline Creatinine & 0.7 & $\mathrm{mg} / \mathrm{dL}$ \\
\hline eGFR & 64.5 & $\mathrm{~mL} / \mathrm{min}$ \\
\hline CRP & 0.8 & $\mathrm{mg} / \mathrm{dL}$ \\
\hline TSH & 0.363 & $\mu \mathrm{IU} / \mathrm{mL}$ \\
\hline FT4 & 1.59 & $\mathrm{ng} / \mathrm{dL}$ \\
\hline \multicolumn{3}{|l|}{ Immunology } \\
\hline $\operatorname{IgG}$ & 2,042 & $\mathrm{mg} / \mathrm{dL}$ \\
\hline $\operatorname{Ig} M$ & 105 & $\mathrm{mg} / \mathrm{dL}$ \\
\hline IgG4 & 70 & $\mathrm{mg} / \mathrm{dL}$ \\
\hline ANA & 80 & Dil \\
\hline AMA (M2) & $<1.5$ & Index \\
\hline anti-LKM1 Ab & $<5$ & Index \\
\hline anti-thyroperoxidase $\mathrm{Ab}$ & 10 & $\mathrm{IU} / \mathrm{mL}$ \\
\hline anti-thyroglobulin $\mathrm{Ab}$ & 11 & $\mathrm{IU} / \mathrm{mL}$ \\
\hline anti-SSA Ab & $<1.0$ & $\mathrm{U} / \mathrm{mL}$ \\
\hline anti-SSB Ab & $<1.0$ & $\mathrm{U} / \mathrm{mL}$ \\
\hline PAIgG & 208 & ng $/ 10^{\wedge} 7$ cells (normal range $\leqq 46$ ) \\
\hline HLA-DR & & DR4, DR15 \\
\hline \multicolumn{3}{|l|}{ Infectious Makers } \\
\hline $\mathrm{HCVAb}$ & $(-)$ & \\
\hline HCV-RNA & $(-)$ & \\
\hline HBsAg & $(-)$ & \\
\hline $\mathrm{HBcAb}$ & $(-)$ & \\
\hline HAV-IgM & $(-)$ & \\
\hline HEV-IgA & $(-)$ & \\
\hline HTLV-1 Ab & $(-)$ & \\
\hline EBV-IgG & $(+)$ & \\
\hline EBV-IgM & $(-)$ & \\
\hline EBNA & $(+)$ & \\
\hline CMV-IgG & $(+)$ & \\
\hline CMV-IgM & $(-)$ & \\
\hline VZV-IgG & $(+)$ & \\
\hline VZV-IgM & $(-)$ & \\
\hline HSV-IgG & $(+)$ & \\
\hline
\end{tabular}

TABLE 1: Continued.

\begin{tabular}{l}
\hline HSV-IgM \\
H. pylori Ab
\end{tabular}

Her vital signs were stable and physical findings were normal except for jaundice and purpura of her legs. The laboratory findings were as follows: total bilirubin, $8.8 \mathrm{mg} / \mathrm{dL}$; aspartate aminotransferase (AST), 1,767 U/L; alanine aminotransferase (ALT), 1,845 U/L; $\gamma$-glutamyl transpeptidase, 2,229 $\mathrm{U} / \mathrm{L}$; alkaline phosphatase (ALP), $845 \mathrm{U} / \mathrm{L}$; immunoglobulin G (IgG), 2,042 mg/dl; anti-nuclear antibody (ANA) titer, positive at 80 -fold dilution; platelet count, $22,000 / \mu \mathrm{L}$; plateletassociated IgG (PAIgG), $208 \mathrm{ng} / 10^{\wedge} 7$ cells. Serologic markers for hepatitis A, B, C, and E viruses, and Epstein-Barr virus, cytomegalovirus, varicella zoster virus, and herpes simplex virus were all negative, and anti-Helicobacter pylori (H. pylori) IgG was positive (Table 1). Abdominal ultrasonography and enhanced computed tomography revealed no significant biliary tract disease that could have led to liver damage.

According to the criteria of the International Autoimmune Hepatitis Scoring System, the patient's pretreatment clinical score without histology was 13 (female: +2; ALP/ALT ratio: +2 ; IgG level: +1 ; ANA titer: +2 , antimitochondrial antibody: 0; viral markers: +3 ; drugs: +1 ; alcohol: 0 ; immune disease: +2 ), indicating probable AIH. Her severe thrombocytopenia was considered to be due to concomitant ITP because of her clinical and laboratory findings.

Liver biopsy via the transjugular route (TJLB) was selected to confirm the diagnosis of AIH to avoid the risk of hemorrhage after percutaneous liver biopsy (PLB) in a patient with severe thrombocytopenia. The right internal jugular vein was punctured after administering local anesthesia, and a 5-Fr catheter cannulated into the right hepatic vein (RHV) over the guide wire. A venogram was performed to confirm the position of the catheter in the RHV (Figure 1(a)). The catheter was then exchanged for a transjugular liver access and biopsy set catheter (Cook Medical, Bloomington, IN). Five liver biopsy specimens were obtained. All steps were performed using X-ray fluoroscopy to confirm the location of the guide wire or catheter. A postbiopsy venogram revealed no complications, including intraperitoneal hemorrhage (Figure 1(b)). Manual compression of the access site on her neck was applied from catheter removal until hemostasis was achieved.

The histological findings of liver biopsy showed interface hepatitis and moderate to severe inflammatory infiltrates 


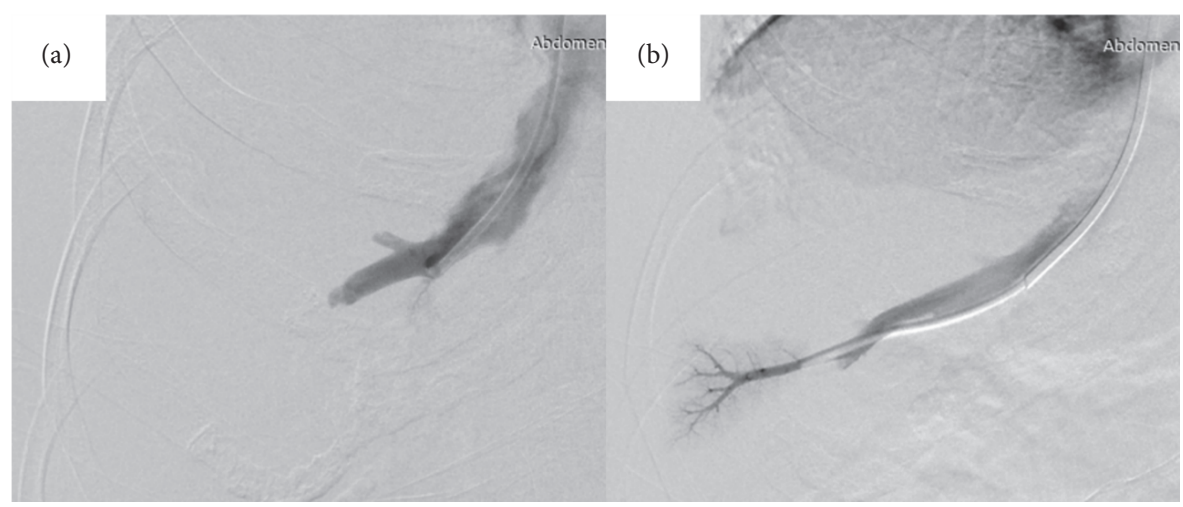

FIgURE 1: Transjugular liver biopsy was performed under X-ray fluoroscopy guidance. (a) A venogram showing a 5-Fr catheter inserted into the right hepatic vein. (b) A postbiopsy venogram, showing no leakage of contrast agent to the outside of the liver.

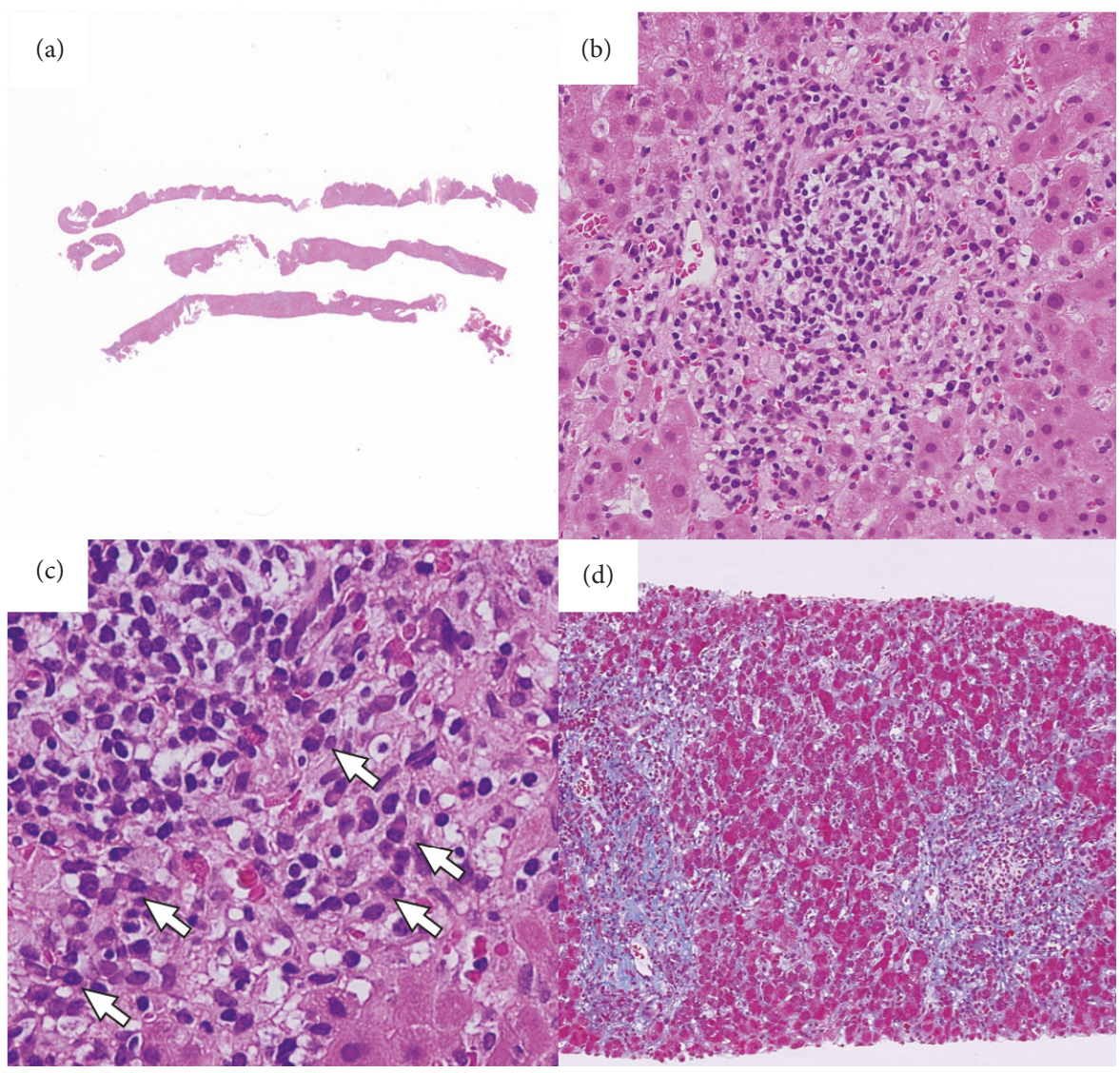

Figure 2: The histological findings of liver biopsy. (a) The specimens of transjugular liver biopsy. (b, c) Interface hepatitis with moderate inflammation and infiltrates of lymphocytes and plasma cells (arrows) in the portal area (b, magnification: $\times 200$. Hematoxylin and eosin staining; c, magnification: $\times 400$; hematoxylin and eosin staining). (d) Moderate fibrosis in the portal area and partial destruction of the hepatic lobules with piecemeal necrosis (magnification: $\times 40$; Masson's trichrome staining).

including lymphocytes and plasma cells. Moderate fibrosis in the portal area and partial destruction of the hepatic lobules with partial piecemeal necrosis was also observed (Figures 2(a), 2(b), 2(c), and 2(d)). All these pathological findings were compatible with the diagnosis of $\mathrm{AIH}$, and the postbiopsy score was 17 , thereby confirming the diagnosis of AIH. Bone marrow aspiration revealed a normal nucleated cell count and a slight increase in megakaryocytes, suggestive of ITP (Figure 3). She received an intravenous glycyrrhizincontaining herbal medicine, Stronger Neo-Minophagen C 


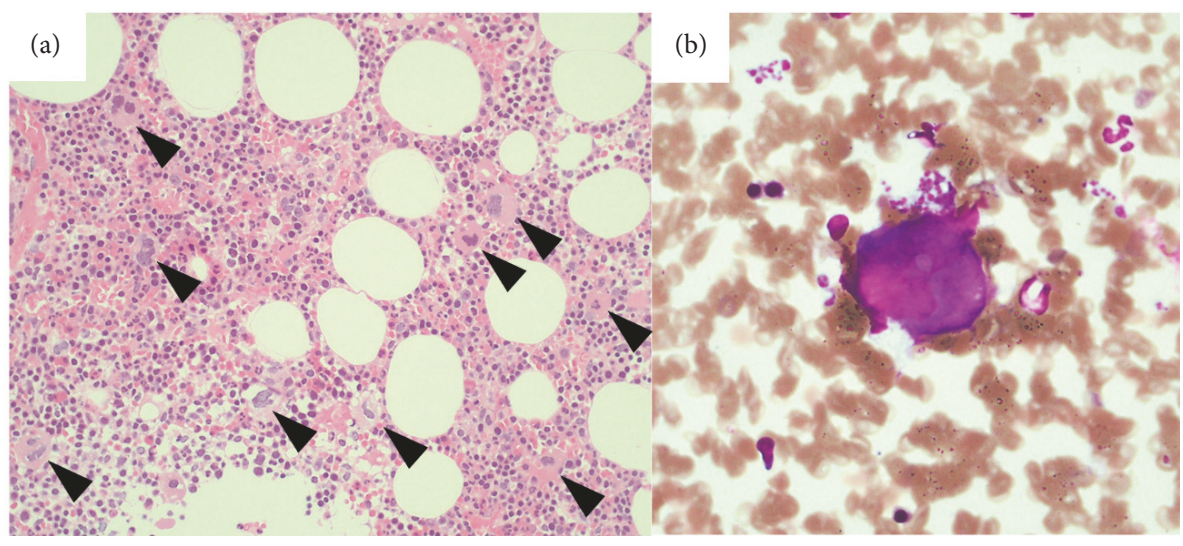

Figure 3: The histological findings of bone marrow biopsy and aspiration. (a) The bone marrow was normocellular with increased megakaryocytes (arrow heads) (magnification: $\times 200$; hematoxylin and eosin staining). (b) Few platelets were visualized around and near the megakaryocytes (magnification: $\times 400$; Wright-Giemsa staining).

(SNMC; Minophagen Pharmaceutical, Tokyo, Japan) at $60 \mathrm{ml} /$ day before TJLB, and prednisolone (PSL) at $55 \mathrm{mg} /$ day $(0.8 \mathrm{mg} / \mathrm{kg} /$ day $)$ after the histological diagnosis of AIH. After PSL administration, the patient demonstrated a good response with restored liver enzyme levels and platelet counts (Figure 4). PSL was tapered to $5 \mathrm{mg}$ /day as a maintenance dose. The patient recovered uneventfully except for a hyperglycemic event requiring insulin treatment.

\section{Discussion}

The present case demonstrates two important clinical points: patients with AIH may sometimes have concomitant ITP, and TJLB is a valuable modality for the diagnosis of AIH with ITP.

With regards to the first point, both AIH and ITP are autoimmune-mediated disorders. AIH is defined as a chronic progressive liver disease caused by unknown etiological factors that is associated with aberrant autoreactivity and a genetic predisposition. In contrast, ITP is caused by immune system dysregulation and the development of autoantibodies for platelet surface glycoproteins (GP) including GPIIb-IIIa, GPIb-IX, and GPIa-II $[3,4]$. The prevalence of ITP among patients with AIH in Japan is reported to be $0.6 \%$ [2], and there are numerous previous case reports of $\mathrm{AIH}$ associated with ITP [5-12]. Although the frequency of autoantibodies against platelet surface GP in patients with $\mathrm{AIH}$ remains poorly understood [7-9], some previous reports described that HLA class II genes, which are associated with susceptibility to AIH, influence the production of anti-GP antibody specificities, suggesting a relationship between AIH and ITP $[13,14]$.

The presence of autoimmune diseases other than ITP should be noted on clinical practice. Although not admitted in this case, there are numerous previous reports of $\mathrm{AIH}$ complicated with other autoimmune diseases in addition to ITP, such as primary biliary cholangitis, Sjögren's syndrome, and chronic thyroiditis $[2,8-12]$.
Corticosteroids are the first-line therapy for both $\mathrm{AIH}$ and ITP, similar to several other autoimmune diseases. Our patient showed immediate improvement of liver function and elevation of platelet count after treatment with PSL.

Our report also showed how TJLB was effective for the diagnosis of AIH with severe thrombocytopenia due to ITP. As mentioned above, histological examination is important for the diagnosis of AIH. The most common approach to obtaining liver tissue is PLB, whose major possible complication is postprocedure hemorrhage. Therefore, it is contraindicated for patients with severe thrombocytopenia. TJLB has been most commonly performed in patients in whom the risks of conventional PLB were deemed unacceptable. In theory, bleeding into the extravascular or abdominal cavity does not occur during TJLB as the liver tissue is obtained through a cannula introduced into the hepatic vein using jugular venous access. Previous reports of TJLB have consistently reported complication rates of $1.3-6.5 \%$, lower than those after PLB $[15,16]$. With recent developments and improvements in devices, the quality of TJLB specimens has become comparable to those obtained with PLB $[17,18]$. In our case, the liver specimen obtained after five punctures during TJLB was sufficient to make a histological diagnosis of AIH. Postprocedure angiography confirmed that bleeding and liver penetration did not occur. We elected to confirm the histological diagnosis by TJLB preceding treatment for the following two reasons: (i) confirming the histological diagnosis as soon as possible and (ii) avoiding overlooking other potential diagnoses, such as hepatic lymphoma, and preventing the effects of PSL on liver tissue, which may make histological diagnosis difficult. However, in hospitals wherein TJLB is unavailable, PLB might be considered after increasing the platelet count by corticosteroid administration. Previous reviews on $H$. pylori infection in patients with ITP have shown that eradication of $H$. pylori infection in patients with ITP results in increased platelet counts in about half of the cases; therefore, eradication treatment is recommended [19-21]. However, in this case, because there was a risk of exacerbation of liver damage, no eradication therapy was 


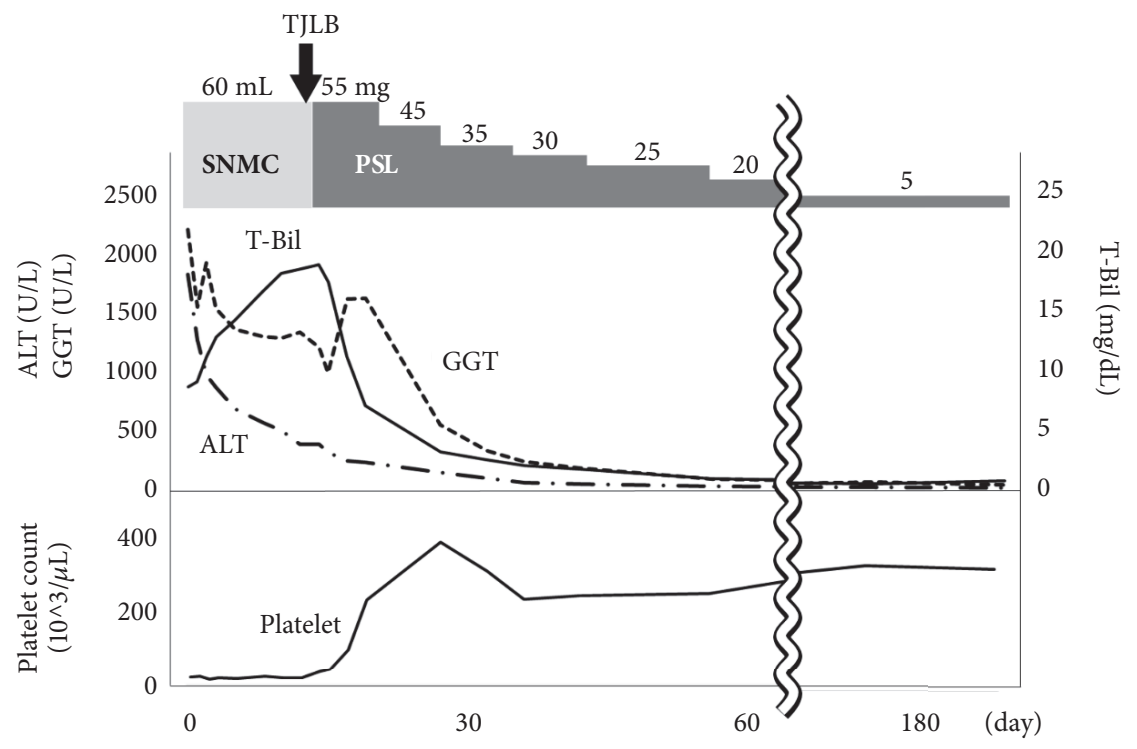

FIGURE 4: Clinical course. T-Bil: total bilirubin; ALT: alanine aminotransferase; GGT: gamma-glutamyl transferase; TJLB: transjugular liver biopsy; SNMC: Stronger Neo-Minophagen C; PSL: prednisolone.

administered. Lusutrombopag, which is an oral thrombopoietin receptor agonist that reduces severe thrombocytopenia in patients with chronic liver disease who are scheduled to undergo an invasive procedure, may be a useful drug in this patient. [22]

The indications for TJLB include not only coagulation disorders, but also the presence of ascites, morbid obesity, previous liver transplant, acute liver failure, and patients in whom a PLB has failed [16].

In conclusion, patients with $\mathrm{AIH}$ may sometimes have concomitant ITP. TJLB was effective for making the diagnosis of AIH with severe thrombocytopenia due to ITP.

\section{Conflicts of Interest}

The authors declare that there are no conflicts of interest regarding the publication of this paper.

\section{References}

[1] E. L. Krawitt, "Autoimmune hepatitis," The New England Journal of Medicine, vol. 354, no. 1, pp. 54-66, 2006.

[2] A. Takahashi, T. Arinaga-Hino, H. Ohira et al., "Autoimmune hepatitis in Japan: trends in a nationwide survey," Journal of Gastroenterology, vol. 52, no. 5, pp. 631-640, 2017.

[3] D. B. Cines and V. S. Blanchette, "Medical progress: immune thrombocytopenic purpura," The New England Journal of Medicine, vol. 346, no. 13, pp. 995-1008, 2002.

[4] B. H. Chong and S.-J. Ho, "Autoimmune thrombocytopenia," Journal of Thrombosis and Haemostasis, vol. 3, no. 8, pp. 17631772, 2005.

[5] A. Ito, K. Yoshizawa, K. Fujimori, S. Morita, T. Shigeno, and T. Maejima, "Autoimmune hepatitis associated with immune thrombocytopenic purpura," Internal Medicine, vol. 56, no. 2, pp. 143-147, 2017.

[6] Y. Nagase, C. Okuse, M. Mugikura et al., "A case of autoimmune hepatitis associated with idiopathic thrombocytopenia," Kanzo, vol. 46, no. 6, pp. 352-358, 2005.

[7] E. S. Santos, L. R. Arosemena, L. E. Raez, C. O’Brien, and A. Regev, "Successful treatment of autoimmune hepatitis and idiopathic thrombocytopenic purpura with the monoclonal antibody, rituximab: Case report and review of literature," Liver International, vol. 26, no. 5, pp. 625-629, 2006.

[8] N. Yamaike, K. Saigo, S. Imoto et al., "Autoimmune hepatitis accompanied by idiopathic thrombocytopenic purpura and Sjögren's syndrome," Internal Medicine, vol. 41, no. 1, p. 72, 2002.

[9] R. Koyamada, T. Higuchi, A. Kitada et al., "Association of primary biliary cirrhosis-autoimmune hepatitis overlap syndrome with immune thrombocytopenia and Graves' disease," Internal Medicine, vol. 54, no. 16, pp. 2013-2016, 2015.

[10] M. Wada, H. Kamimoto, S. Y. Park, S. Shintani, and K. Nakasho, "Autoimmune hepatitis concomitant with hypergammaglobulinemic purpura, immune thrombocytopenia, and Sjögren's syndrome," Internal Medicine, vol. 40, no. 4, pp. 308-311, 2001.

[11] M. Toyoda, H. Yokomori, F. Kaneko et al., "Primary biliary cirrhosis-autoimmune hepatitis overlap syndrome concomitant with systemic sclerosis, immune thrombocytopenic purpura," Internal Medicine, vol. 48, no. 23, pp. 2019-2023, 2009.

[12] Y. Arakawa, S. Amaki, H. Miyakawa et al., "PBC-AIH overlap syndrome with concomitant ITP and Hashimoto's disease with positivity for anti-centromere antibody," Journal of Gastroenterology, vol. 39, no. 5, pp. 490-495, 2004.

[13] T. Umemura, Y. Katsuyama, K. Yoshizawa, T. Kimura, and S. Joshita, "Human leukocyte antigen class II haplotypes affect clinical characteristics and progression of type 1 autoimmune hepatitis in Japan," PLoS ONE, vol. 9, no. 6, Article ID e100565, 2014. 
[14] M. Kuwana, J. Kaburaki, J. P. Pandey et al., "HLA class II alleles in Japanese patients with immune thrombocytopenic purpura. Associations with anti-platelet glycoprotein autoantibodies and responses to splenectomy," Tissue Antigens, vol. 56, no. 4, pp. 337-343, 2000.

[15] G. Kalambokis, P. Manousou, S. Vibhakorn et al., “Transjugular liver biopsy - Indications, adequacy, quality of specimens, and complications - A systematic review," Journal of Hepatology, vol. 47, no. 2, pp. 284-294, 2007.

[16] J. Wedemeyer, M. G. Beckmann, M. J. Bahr et al., "Clinical relevance of transjugular liver biopsy in comparison with percutaneous and laparoscopic liver biopsy," Gastroenterology Research and Practice, 2009.

[17] G. Behrens and H. Ferral, “Transjugular liver biopsy," Seminars in Interventional Radiology, vol. 29, no. 2, pp. 111-117, 2012.

[18] G. Behrens, H. Ferral, D. Giusto, J. Patel, and D. H. Van Thiel, "Transjugular liver biopsy: Comparison of sample adequacy with the use of two automated needle systems," Journal of Vascular and Interventional Radiology, vol. 22, no. 3, pp. 341345, 2011.

[19] M. Franchini and D. Veneri, "Helicobacter pylori-associated immune thrombocytopenia," Platelets, vol. 17, no. 2, pp. 71-77, 2006.

[20] N. Teawtrakul, K. Sawadpanich, C. Sirijerachai, K. Chansung, and C. Wanitpongpun, "Clinical characteristics and treatment outcomes in patients with Helicobacter pylori-positive chronic immune thrombocytopenic purpura," Platelets, vol. 25, no. 7, pp. 548-551, 2014.

[21] G. H. Frydman, N. Davis, P. L. Beck, and J. G. Fox, "Helicobacter pylori Eradication in Patients with Immune Thrombocytopenic Purpura: A Review and the Role of Biogeography," Helicobacter, vol. 20, no. 4, pp. 239-251, 2015.

[22] E. S. Kim, "Lusutrombopag: First Global Approval," Drugs, vol. 76, no. 1, pp. 155-158, 2016. 


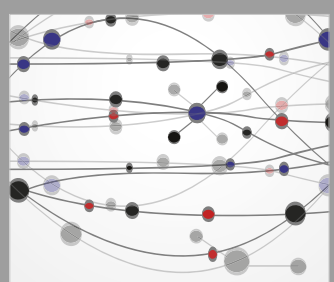

The Scientific World Journal
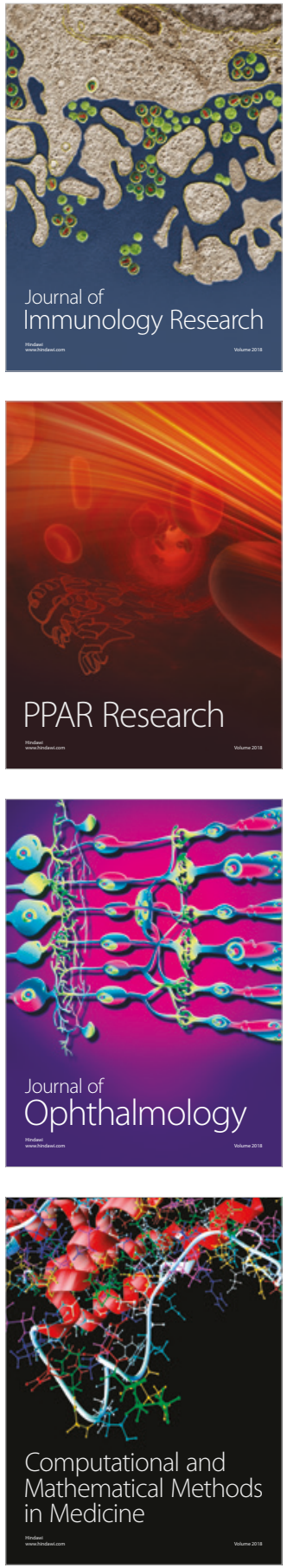

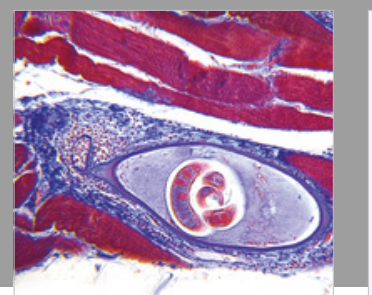

Gastroenterology Research and Practice

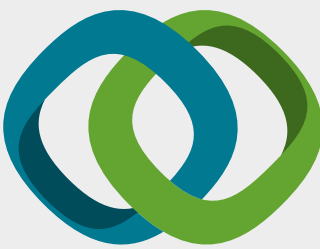

\section{Hindawi}

Submit your manuscripts at

www.hindawi.com
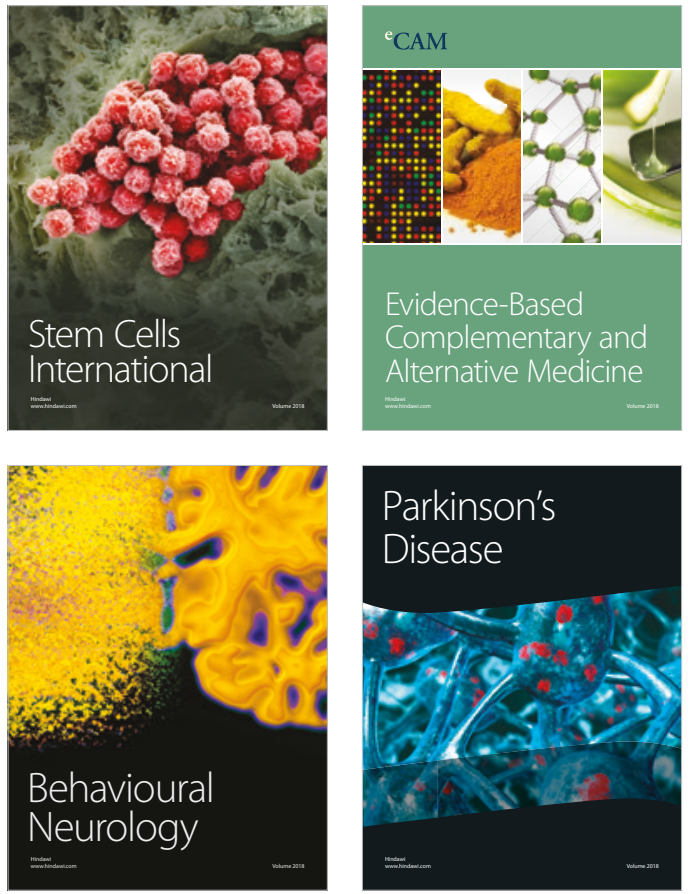

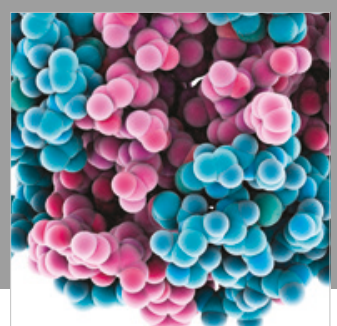

ournal of

Diabetes Research

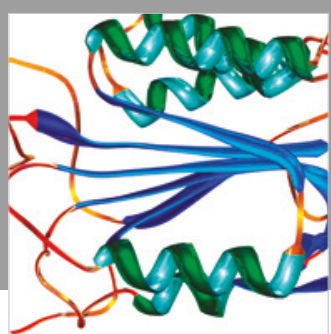

Disease Markers
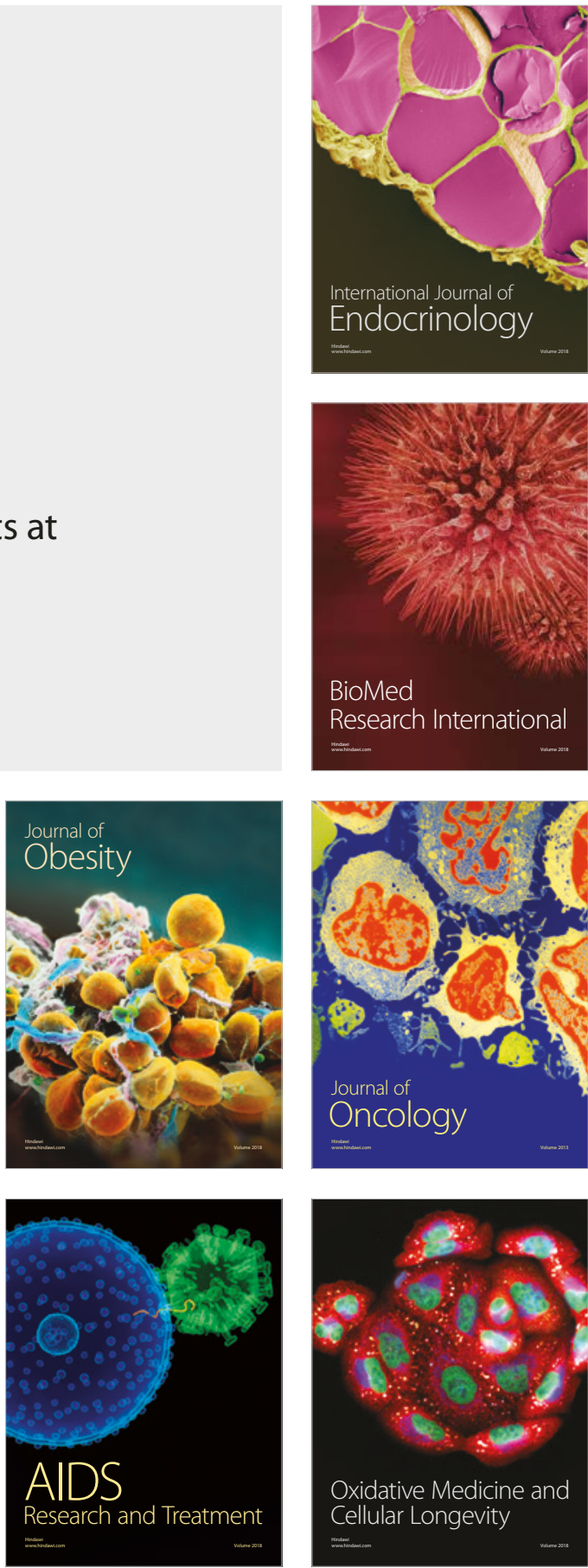